\title{
Apparent parental care in the slow worm Anguis fragilis
}

\author{
JAMIE NEAVES ${ }^{1,2 *} \&$ ROB GANDOLA ${ }^{3}$ \\ ${ }^{1}$ Thames Basin Heaths Partnership \\ ${ }^{2}$ Surrey Amphibian and Reptile Group \\ ${ }^{3}$ Herpetological Society Ireland, Dublin, Ireland \\ ${ }^{*}$ Corresponding author e-mail: jamie.neaves@naturalengland.org.uk
}

$T^{T}$ he slow worm (Anguis fragilis) is a limbless anguid lizard native to Great Britain. This semi-fossorial lizard has a wide distribution across Europe and can be found in a variety of habitats with a preference for high levels of ground cover, where for most of the time it remains hidden in thick vegetation or underground (Beebee \& Griffiths, 2000). While A. fragilis is possibly the most commonly encountered native reptile in Britain, and many aspects of slow worm biology are understood, their cryptic habits make them difficult to study. Much of what is known about slow worm behavioural ecology comes from observations associated with artificial cover objects (refuges) commonly utilised in reptile surveys (Mclnerny \& Minting, 2016). Communal basking and hibernation assemblies involving multiple age groups of slow worms entwined together have been recorded underneath refuges, with other reptile species also regularly present (Wareham, 2008; Mclnerny, 2017). How the individual slow worms are related to one another in these assemblages is usually not known and the genetic tools required to create such pedigrees are usually beyond the scope of most reptile surveys. It would be logical to assume that in a species with limited dispersal capacity and small home ranges, as is the case with $A$. fragilis, many of the individuals seen together would be closely related. Therefore, it is not unreasonable to make inferences on their behaviour based on this assumption.

Evidence of parental care in $A$. fragilis is lacking but it is known in other anguid lizard species, with some oviparous species exhibiting clutch guarding behaviours and subsequent attendance of neonates (Greene et al., 2006). Previous observations of captive $A$. fragilis females suggest they may actively attend their young, but do not exclude the possibility that observations come from passive sharing of refuges (Greene et al., 2006). Mclnerny and Minting (2016) suggest that postpartum care in slow worms is limited with neonates moving away from the natal site quickly after birth.

Here we report on an observation that may constitute an incidence of parental care in slow worms. At 09:43 h on 27th August 2020 two adult female $A$. fragilis (TL $\sim 24 \mathrm{~cm}$ and $\sim 25.5 \mathrm{~cm}$ ) and five neonates were found under a metal survey refuge during a search for survivors after a wildfire on Chobham Common NNR, Surrey, (GPS: $51^{\circ} 23^{\prime} 13^{\prime \prime} \mathrm{N} 00^{\circ}$ $\left.36^{\prime} 58^{\prime \prime} \mathrm{W}\right)$. On initial discovery, the lizards were sheltering communally, with some individuals clustered together and overlying, with others separate from this group. All lizards under this refuge were collected into a plastic box (Fig. 1)

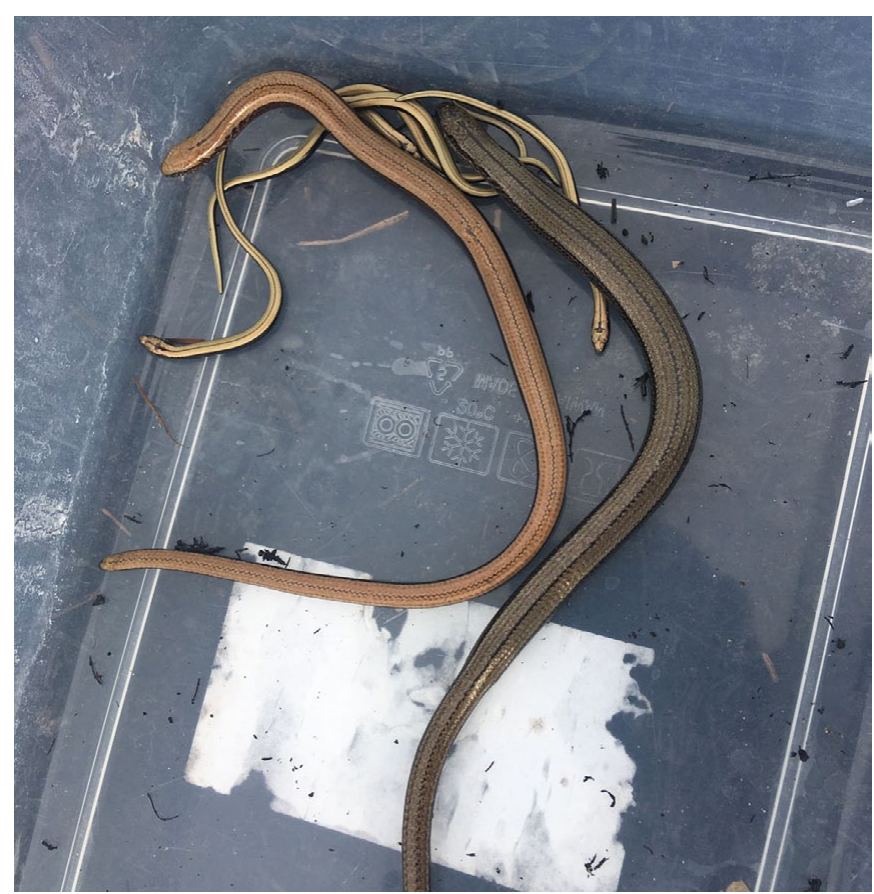

Figure 1. Two adult female and five neonate Anguis fragilis collected from under a refuge after a wildfire

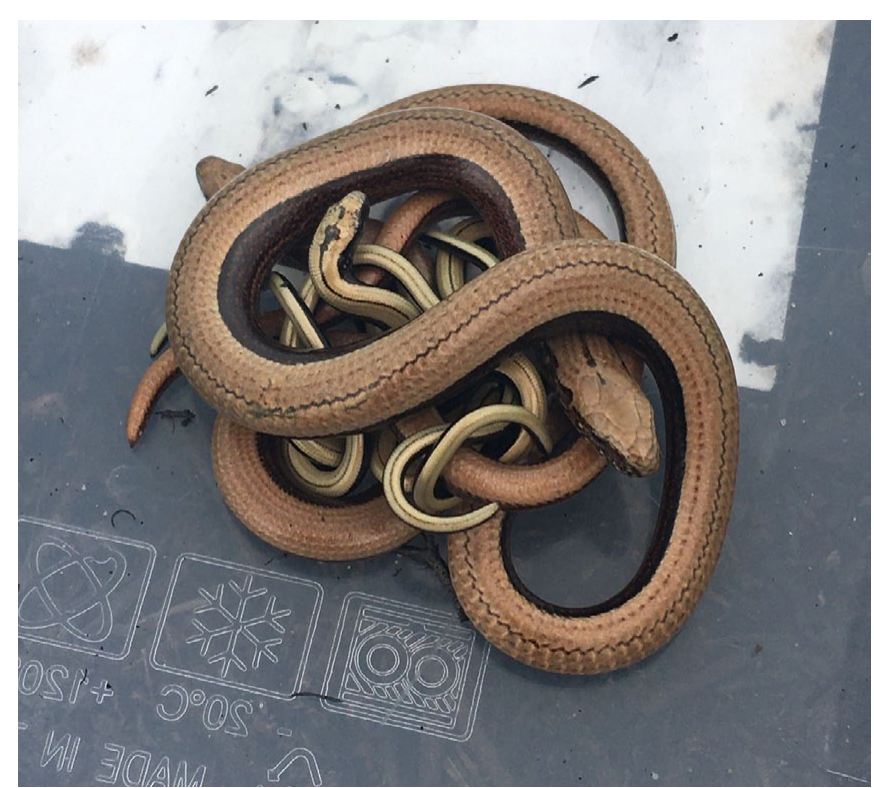

Figure 2. One adult female Anguis fragilis coiling around one subadult and four neonates approximately 30 minutes after collection 
with a cloth bag placed over the top to reduce stress. An additional subadult female slow worm (TL $\sim 17 \mathrm{~cm}$ ) was also rescued from a separate refuge and added to the box. At $10: 16 \mathrm{~h}$ the cloth bag was removed for release, revealing an adult female $A$. fragilis coiled up with four of the neonates and the subadult (Fig. 2). The larger adult female and the fifth juvenile were separate from the coiled group and remained motionless upon removal of the cover. Shortly after the photograph was taken the subadult female left the coiled group. For more details see our video (BHS video, 2021).

Whilst communal sharing of refuges has been recorded (Wareham, 2008), parental care in wild $A$. fragilis has not been previously documented. In England, captive females have been known to have coiled with their young in a hollow on the day of birth (Anne Riddell, pers. comm.) and "... tended to be scattered under the refuges and rarely coiled up together" (Greene et al., 2006). To our knowledge this is the first observation of wild $A$. fragilis displaying a behaviour akin to juvenile defence, based on the assumption that the adult female is the mother of the juveniles.

The response of these slow worms to capture raises interesting questions on the role pheromone release may play in eliciting the defensive coiling behaviour seen. Conversely, it is also debatable that proximity may play a greater role in attracting members of a defensive coil during a stress event. That a subadult individual, with an unknown relationship to the assumed parent-neonate grouping, also formed part of the coil also raises interesting questions given that one neonate did not join the coil or, at least, was triggered to abandon the coil upon disturbance associated with removing the cloth bag cover. Kin recognition through olfactory cues is known between common lizard, Zootoca vivipara, mothers and their offspring (Léna \& de Fraipont, 1998) and male slow worms have been shown to discriminate between conspecific male and female scents (Gonzalo et al., 2004). The observation could also be attributed to thigmotactic behaviour, where the slow worms may simply have wrapped around each other for stability due to the lack of suitable substrate in the plastic container. Further investigation is needed to assess parental care, defensive behaviours, and kin recognition in $A$. fragilis.
While this observation does not definitively provide a record of parental care in $A$. fragilis, it does corroborate previous observations by Anne Riddell and provides evidence for our suggestion that slow worms engage in altruistic defensive behaviours. It is also likely that this defensive coiling behaviour occurs at much greater frequencies but has gone unnoticed. At its most basic, this report should encourage debate and adds to the limited knowledge on the behavioural ecology of slow worms.

\section{REFERENCES}

Beebee, T. J. C. \& Griffiths, R. A. (2000). Amphibians and Reptiles: A Natural History of the British Herpetofauna. London. HarperCollins, 270 pp.

BHS video (2021). Apparent parental care in the slow worm Anguis fragilis. https://youtu.be/9hR-1muyl8Q

Galán, P. \& Ferreiro, R. (2004). Reproductive ecology of the slow worm (Anguis fragilis) in the northwest Iberian Peninsula. Animal Biology 54: 353-371.

Gonzalo, A., Cabido, C., Martín, J. \& López, P. (2004). Detection and discrimination of conspecific scents by the anguid slow-worm Anguis fragilis. Journal of Chemical Ecology 30: 1565-1573.

Greene, H. W., Rodríguez, J. J. S. \& Powell, B. J. (2006). Parental behavior in anguid lizards. South American Journal of Herpetology 1: 9-19.

Léna, J. P. \& de Fraipont, M. (1998). Kin recognition in the common lizard. Behavioral Ecology and Sociobiology 42: 341-347.

Mclnerny, C.J. \& Minting, P.J. (2016). The Amphibians and Reptiles of Scotland. Glasgow: Glasgow Natural History Society. $320 \mathrm{pp}$.

Mclnerny, C. J. (2017). Observations on co-existing populations of adders, slow-worms and common lizards at Loch Lomond, Scotland: implications for conservation. The Glasgow Naturalist 26: 15-24.

Wareham, D. C. (2008). The Reptiles and Amphibians of Dorset. The British Herpetological Society, London, 47-52 pp.

Accepted: 16 November 2020 